\title{
Pulp Mill Integration with Alcohol-to-Jet Conversion Technology
}

Scott Geleynse ${ }^{\mathrm{ab}}$, Zhihua Jiang ${ }^{\mathrm{c}}$, Kristin Brandt ${ }^{\mathrm{d}}$, Manuel Garcia-Perez ${ }^{\mathrm{a}}$, Michael Wolcott ${ }^{\mathrm{d} *}$, Xiao Zhang ${ }^{\mathrm{ab} *}$

${ }^{a}$ Bioproducts, Sciences, and Engineering Laboratory, Washington State University Tri-Cities, Richland WA

${ }^{\mathrm{b}}$ Voiland School for Chemical and Bioengineering, Washington State University, Pullman WA

${ }^{\mathrm{c}}$ Alabama Center for Paper and Bioresource Engineering \& Department of Chemical Engineering, Auburn University, Auburn AL

${ }^{\mathrm{d}}$ Composite Materials and Engineering Center, Washington State University, Pullman WA

Highlights:

- Alcohol-to-jet (ATJ) technology allows biorefineries to produce viable jet fuel blendstock

- Production capacity and energy usage is modeled within pulp mill biorefineries using ATJ

- Fuels conversion offers a relative reduction in energy use from kraft mill pulping 
Technical Report Documentation Page

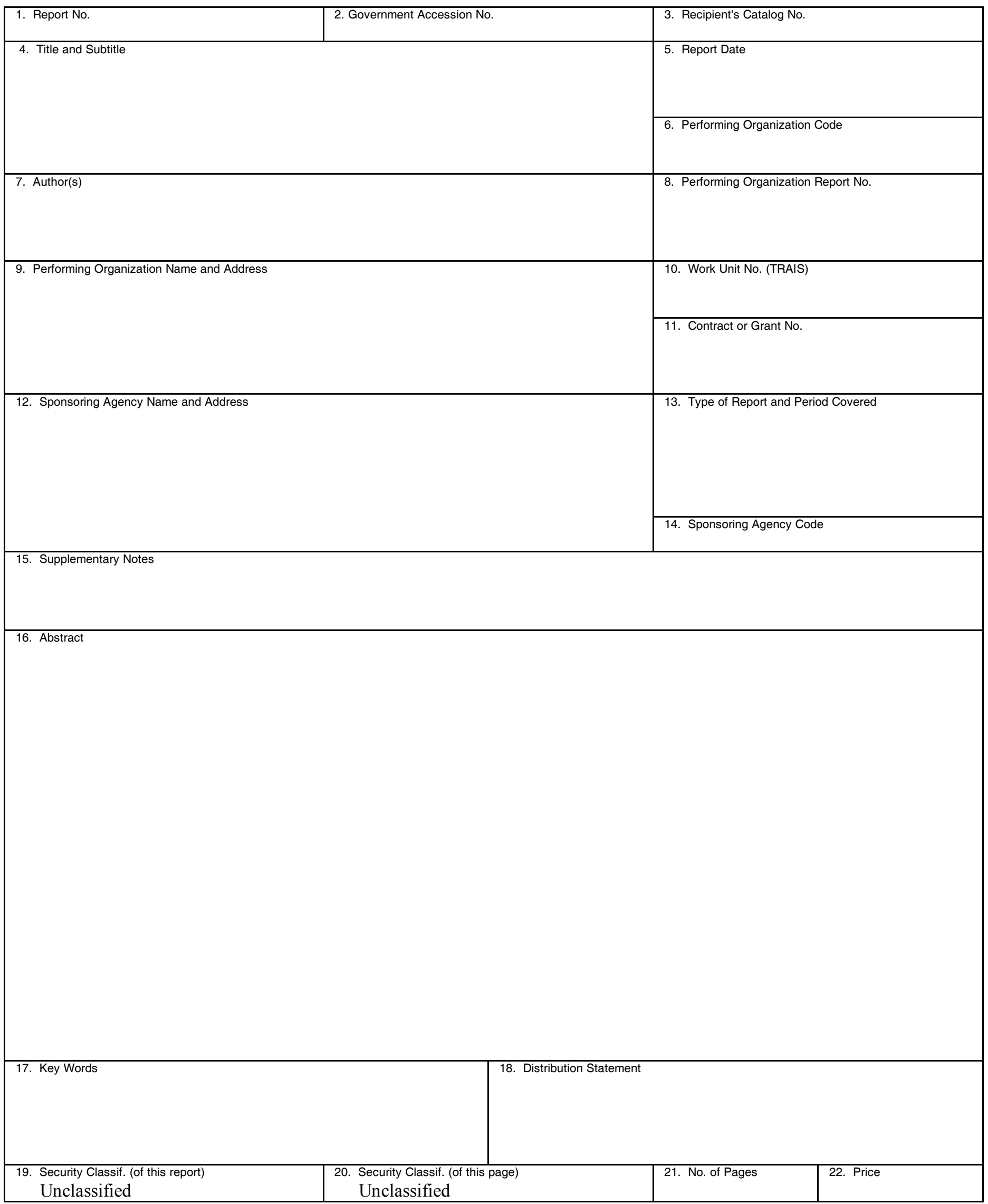

Form DOT F 1700.7 (8-72) Reproduction of completed page authorized




\begin{abstract}
This study examines the integration of commercial liquid fuels production from biomass using the alcohol-to-jet pathway into a conventional kraft pulp mill operation. Mill assets including feed handling and supply chain infrastructure, power and recovery systems, and potential equipment retrofitting opportunities are utilized by a fuel production unit through lignocellulosic ethanol fermentation and alcohol-to-jet processing. Potential economic benefits of integrating the energy recovery system (recovery boiler) of the pulp mill with the biomass pretreatment systems are evaluated through energy and mass balances of the integrated facility. Process variations explored within this model include the use of hemicellulose pre-extraction or black liquor fractionation, modifications to digester operations and the scale of a mill retrofitting project. The production of liquid fuels is found to provide a relative reduction in energy use compared to pulp production. With the low energy costs provided by this design, maintaining a high yield throughout the conversion process and the reduction of capital costs offer the best opportunities for further improving economics. Although the economic viability of a realistic biorefinery is not directly evaluated in this study, the aim is to identify technical barriers and opportunities for development of integrated strategies for implementing proven biofuels production technologies.
\end{abstract}




\section{Introduction and Background}

As the demand and supply for fossil resources will likely shift over time, the aviation industry recognizes the need to secure flexible alternatives for producing the necessary safe and reliable highdensity fuels and begin shifting the market toward sustainable alternatives in the near future[1-3]. Several alternative aviation fuel production processes have successfully been approved for commercial use. Although these pathways may provide the aviation industry new sources for fuel outside of petroleum, the use of alternative feedstocks requires integration of fuels sourcing with new and different supply chains[4]. The integration of the production process for a qualified aviation turbine fuel into an existing industry supply chain may alleviate these problems, particularly in the short term as new fuels production technologies develop.

The Alcohols-to-Jet pathway is an ASTM qualified production process for aviation turbine fuel in which alcohols (either ethanol or isobutanol) are catalytically upgraded to a synthetic kerosene product suitable for use as a jet fuel blendstock up to 50\%[5]. Figure 1.1 summarizes the unit operations and chemical intermediates of the generalized ATJ process. Ethanol or isobutanol is first catalytically dehydrated into ethylene or isobutylene. The oligomerization process is tuned to generate a carbon chain length suitable for fractionation into marketable fuel blendstocks after saturation with hydrogen. is While the alcohol upgrading process requires a considerable amount of energy and capital investment, the primary barrier toward successful commercialization of the pathway lies in the production of alcohol at a low cost[6].

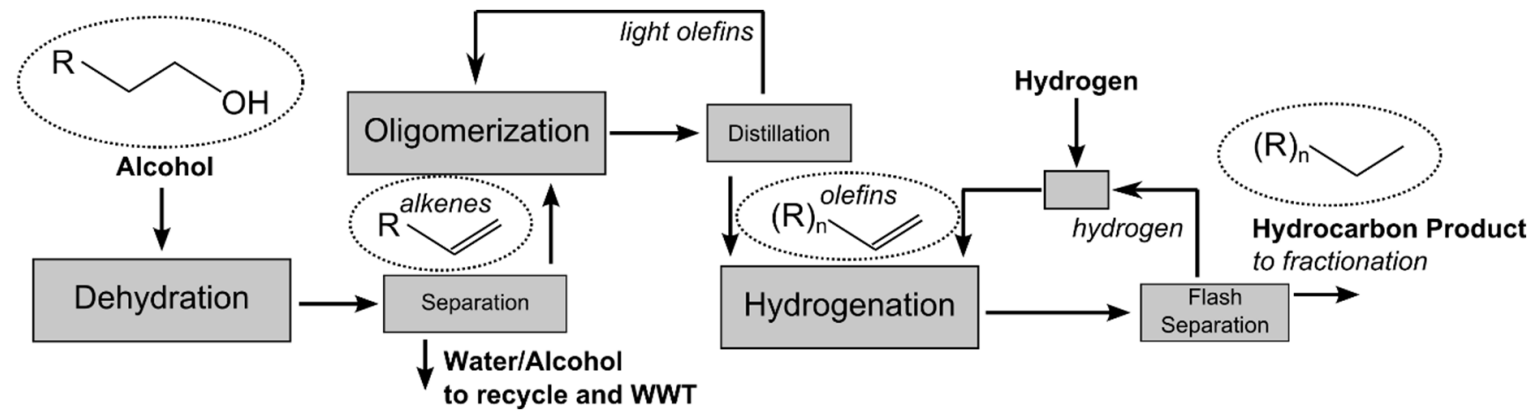

Figure 1.1: The Alcohol-to-Jet Conversion Process. Both ethanol or isobutanol may be used as a feedstock; this paper considers an ATJ process using ethanol produced by fermentation and two-column distillation.

As a composite material, wood contains a variety of chemical structures that may serve as precursors for useful chemicals in addition to pulp production. The pulp industry has long recognized the potential value of recovering fermentable carbohydrates from cellulose and hemicellulose fractions of lignocellulose along the fiber production line, useful for conversion into a wide range of potential chemical products[7-9]. A substantial portion of the remainder of a Kraft pulping mill's feedstock (mostly lignin and hemicellulose fragments) are not transformed into pulp and paper products but are utilized by generating power in the form of heat and electricity to sustain pulping and papermaking process operations. This feature is an attractive solution to improve the economics of an integrated 
biorefinery, reducing energy and chemical costs for the conversion of biomass to fuels and chemicals, but demands significant capital costs and financial risk for such a new industry.

Converting lignocellulose to hydrocarbon fuels is an energy intensive process and the advent of an economically viable standalone lignocellulosic biorefinery remains elusive. On the other hand, the papermaking industry has been utilizing plant materials to produce commodity products in an energy intensive process for over a hundred years. It is sensible to investigate potential synergies where the pulp mill's approach to biomass processing might be used to incorporate biofuels production as well.

In this study, we develop a process economic model of a retrofitted pulp mill in which some fraction of its fiber production process has been converted to produce sustainable alternative jet fuel through fermentation and the ATJ process. In the integrated mill concept, this key interaction is captured by adopting digester technology to function as a biomass pretreatment and allowing the recovery boiler to power the mill, including the energy-hungry processes of alcohol separation and catalytic upgrading required for the ATJ pathway. Two technologies for carbohydrate utilization (preextraction and liquor fractionation) are explored as additional options to further utilize the hemicellulose fraction of the feedstock.

The addition of biorefinery operations to the pulp mill infrastructure has been widely explored in a number of configurations and has been shown to offer a variety of potential energy efficiency and economic benefits through process integration[9-18]. The work in this study expands upon the model concept in multiple ways: first, the complete conversion pathway to a viable drop-in jet fuel blendstock product is considered using the ATJ technology. Second, the limits of the mill integration and retrofitting concept is tested by assessing the energy balance around a mill with chemical and energy recovery systems shared between both fuel production and fiber production operations.

With this assessment, this study does not intend to propose a singular process design for an integrated biorefinery or evaluate the feasibility of a particular operation. Instead, we aim to use data from average mills and predicted technical performance and costs to evaluate the approach. The economic effects of key performance parameters will be assessed to identify technical barriers and opportunities for development of integrated strategies for biofuels production.

\subsection{The Modified Kraft Pulp Mill to ATJ Model}

Most pulp mills in operation today use the Kraft process, which for the purpose of our analysis can be broken down into the process flow diagram shown in Figure 1.2. The production of paper and other fiber products from this pulp is often co-located at the site of the mill, and typical mills will possess multiple fiberlines to produce a variety of pulp types and qualities. 


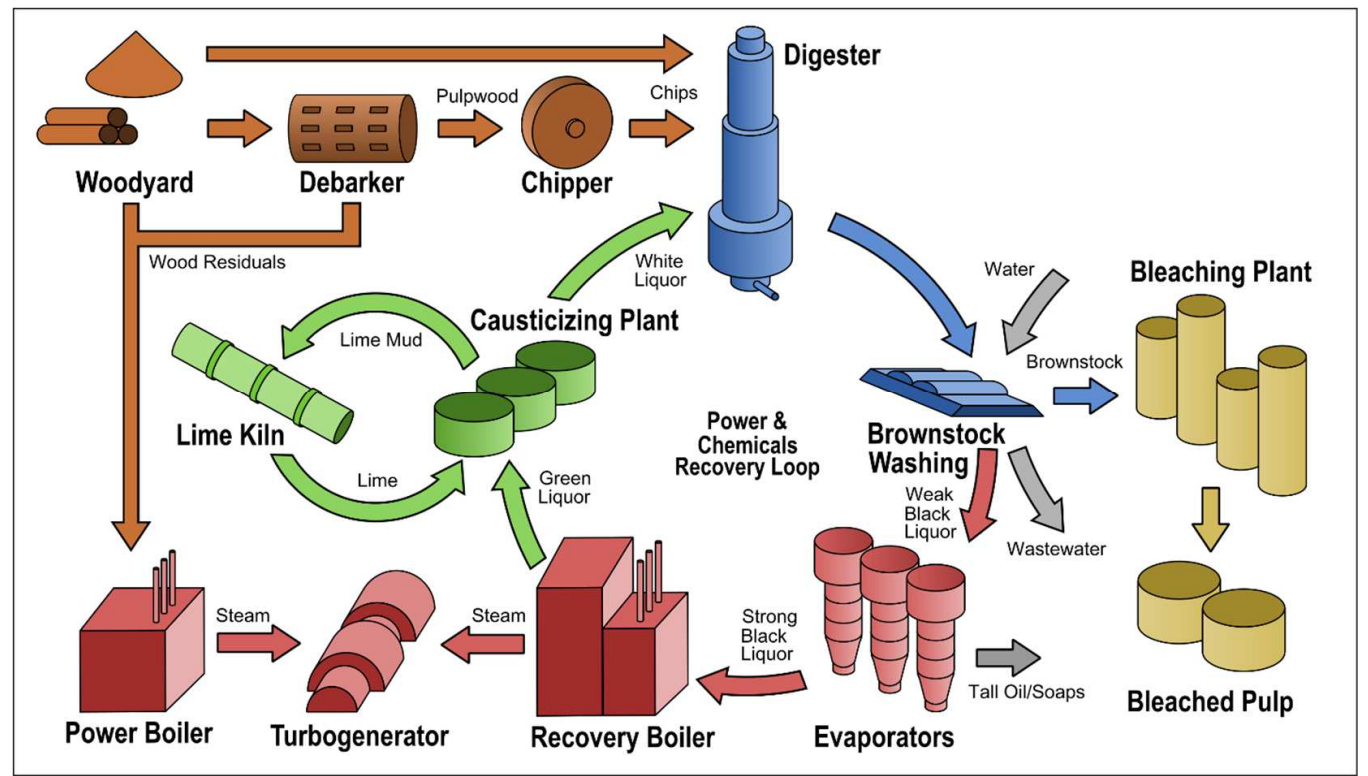

Figure 1.2: Basic Process Flow of a Kraft Pulp Mill, Integrated Recovery Systems, and Bleaching Facility

Kraft pulp mills essentially conduct pulping operations in two major stages. First, chips are processed through digesters utilizing elevated temperatures and a chemical mixture called white liquor. This removes a majority of the lignin and extractives content of the wood along with a portion of hemicellulose and some cellulose. These components are dissolved in the resulting black liquor, leaving a rough pulp product called brownstock. Brownstock is then further refined through a series of additional unit operations typically including oxidative and chlorine bleaching as well as mechanical refining. This secondary area of processing helps to achieve fiber properties such as strength and appearance which are important for the production of paper products.

As a raw material, wood contains much more than carbohydrate polymers in the form of cellulose and hemicellulose, and economical use of wood as a feedstock calls for the recovery of value from lignin and other components. The most consistently practical application of biorefinery lignin to date is to simply recover energy through combustion. Kraft mills achieve this by reprocessing spent digestor chemicals (black liquor) through a process which combusts the dissolved wood components and regenerates the alkaline white liquor. This "Power and Recovery" process loop consists of a significant portion of the capital in a Kraft mill and produces most of the energy (steam and electricity) necessary to maintain economic operation of the entire mill. The combined capital involved in a pulp and paper mill including power and recovery, pulping, and papermaking operations is substantial. In contrast, the typical biorefinery concept relies on lower capital investment in relation to the pulp industry.

The general integration concept explored in this analysis is shown in Figure 1.3. Some portion of the production line is retrofitted to produce liquid fuels by directing unbleached and unrefined brownstock (digested/pretreated lignocellulose) through a new production line including saccharification, fermentation, and alcohol-to-jet conversion. This approach maintains the basic 
operation of the digester units, now functioning as a biomass pretreatment process for fuels production, as well as the power and recovery systems supporting the digesters. The recovery boiler system recovers energy from the combined black liquor stream, assisting in powering all mill operations including the new production units.

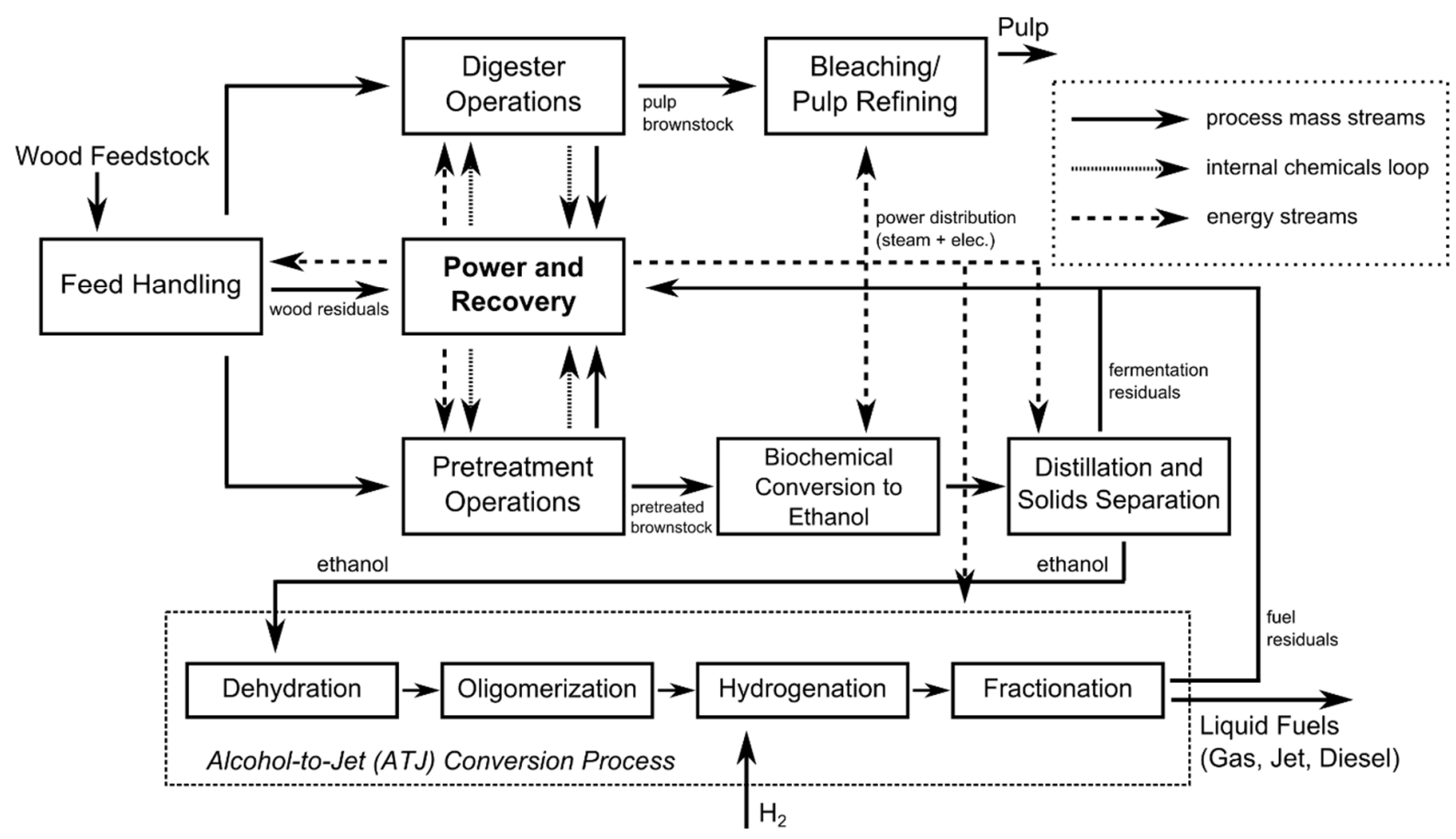

Figure 1.3: Diagram of the Integrated Biorefinery Concept with major process streams, showing the parallel pulp and fuels production structure with shared chemicals and energy recovery facilities.

A typical pulp mill operates multiple fiber lines, which may include multiple different digester and refining units. A mill undergoing the refitting operations detailed here would likely maintain a significant portion of fiber production, but would redirect a portion of brownstock toward fuels production. Brownstock is an intermediate product of the Kraft process, produced after digestion and washing of black liquor. This unrefined pulp product is primarily composed of cellulose fibers but contains a residual level of other components which affect the color and fiber properties. While important for papermaking, these residuals have little additional effect on enzymatic hydrolysis efficacy and further delignification and bleaching is not necessary. A modified digester process can function as a biomass pretreatment, which can by further process by enzymatic treatment to depolymerize carbohydrates; a process called saccharification[19].

Maintaining the energy balance of a pulp mill is critical to its operation as the energy requirements (heat and electricity) for the mill are expensive. Therefore, any changes made in repurposing must consider the effect of energy production and use throughout the process. Redirection of brownstock toward fuels has two major effects on energy use and production: first, the energy usage of saccharification and fuel production replaces the energy requirements of any fiber refining and 
papermaking it would otherwise undergo. Second, residual solids remaining from fermentation may be redirected back to the recovery boiler to produce additional energy.

In this paper, we aim to evaluate the interactions between pulping and fuels conversion operations in an integrated pulp mill biorefinery by modeling the mass and energy balances throughout the process. In addition, capital costs for the retrofit and operating costs of new operations are estimated in order to examine process economics. It is important to note that while our assessments do produce data in the form of total economic costs and minimum selling prices for fuels, these should not be considered as realistic estimates for costs of production in an actual mill. Rather, these results are used to comparatively evaluate the relationships between production volumes and energy balances within the mill, and identify strategies to maximize value in an integrated mill.

\section{Methods}

\subsection{Mill Model Overview}

The integrated pulp mill biorefinery model examines the production process for fresh wood chips feed into hydrocarbon fuels, alongside a separate production line of refined and bleached pulp for papermaking processes. Added costs for the retrofit of pulp production into fuels are estimated, and the impacts of the change on energy balance are modeled; other costs of production which remain relatively unchanged from pulp production are excluded from the model. These substantial costs, along with opportunity costs associated with a mill retrofit, affect the ultimate profitability of any scenario. Thus, production costs estimated by this model are built upon a baseline of mill operations costs for comparative purposes between process implementations. A unit-level flowsheet for the inside battery limits (ISBL) of the process model is shown in Figure 2.1, including the two additional extraction/fractionation unit scenarios tested.

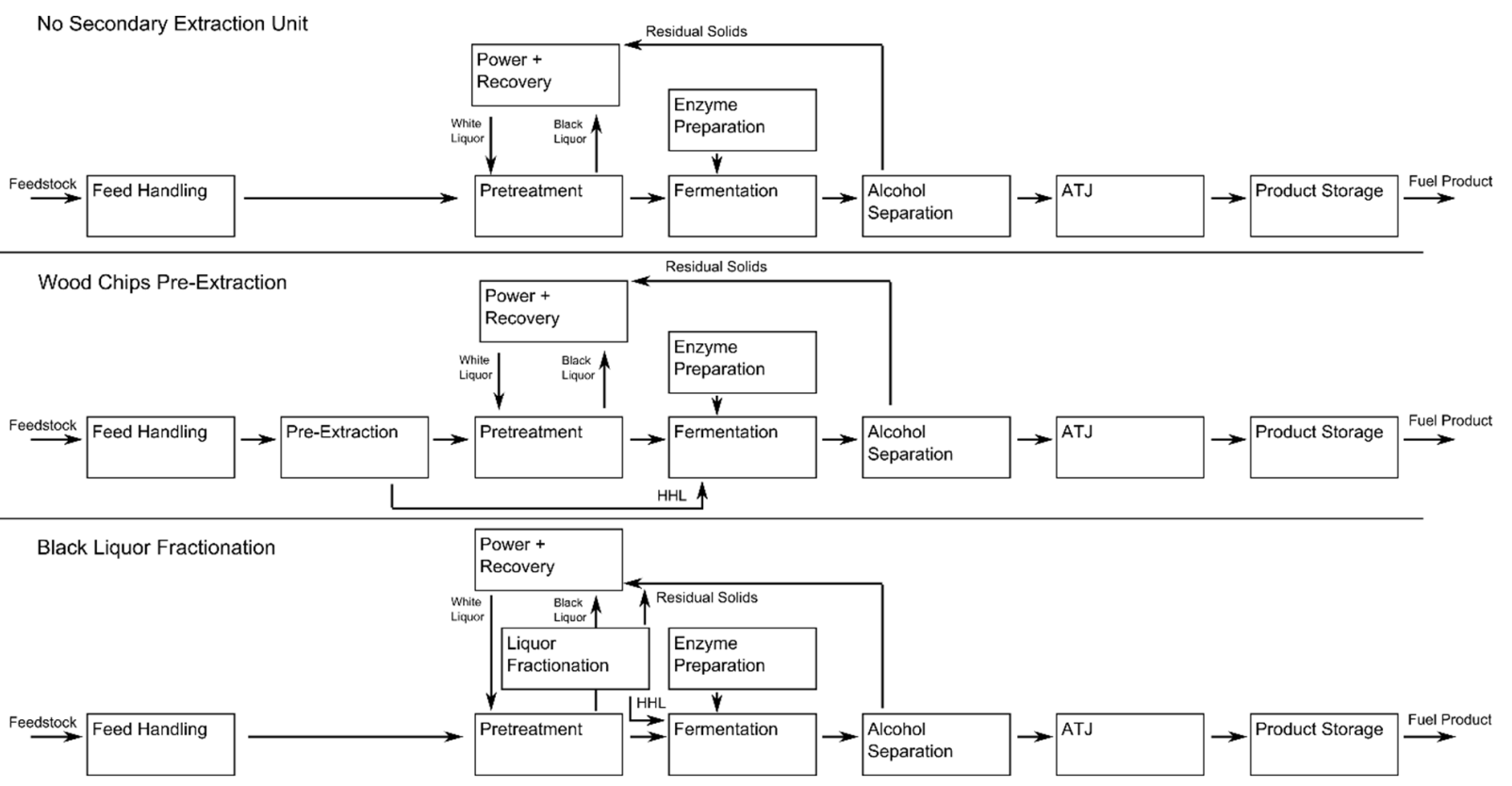


Figure 2.1: Unit-Level Process Diagram Inside the Modeled Battery Limits. Fiber production operations are treated outside battery limits, but black liquor supply and energy consumption is modeled in "whole mill" scenarios.

The integrated biorefinery model is constructed based on modeling framework described by several process and economic models available in literature. A model of unbleached pulp mill operations produced by the Forest Products Laboratory[20] serves as a foundation for digester and energy recovery systems modeling in this process model. Saccharification and fermentation operations are based on the Corn Stover to Ethanol Model produced by NREL[21]. A process economic model of the alcohol-to-jet pathway, producing liquid fuels from ethanol, is available from Geleynse, et. al.[6]. The integrated biorefinery process model was constructed in MS Excel and Aspen Plus V8.8 simulation software was used to construct the ATJ process models. The spreadsheet model is included as a supplementary document with this publication.

\subsection{Process and Economic Modeling Methods and Assumptions}

\subsubsection{Integrated Pulping and Energy Recovery Operations}

Feed to the integrated pulp mill process is based on a typical softwood feedstock. In the base case, the feed is assumed to contain $10 \%$ bark and fines which are fed to the power boiler systems; remaining wood chips fed to digesters are assumed to contain $39 \%$ cellulose, $30 \%$ hemicellulose, $27 \%$ lignin, and $4 \%$ extractives. Digester performance is based on a hypothetical operation at a kappa number of 40 and a pulp yield of $48.3 \%$; components in the pulp are fed to the saccharification unit, while dissolved solids are diverted to recovery operations. Capital costs for the digester retrofit in the base case is based on $33 \%$ costs for an equivalently sized biomass pretreatment reactor system.

Recovery operations assume constant operation of liquor evaporation, kilning, and recausticizing processes. Steam and electricity requirements for these operations are based on average mill data[22] scaled by chips processing rate. Recovery boiler, power boiler, and generator systems are modelled using energy sources across the mill including dissolved solids components fed to the recovery boiler (divided into carbohydrates, lignin, and extractives with $1 \%$ evaporation of dissolved solids) as well as bark/fines, residual fermentation solids, fuel residuals, and any auxiliary hog fuel feed to the power boiler.

A typical recovery boiler operation produces superheated steam, which is used to cogenerate electricity and steam for process use as the steam is expanded and regulated to provide the various pressure steam streams required throughout the mill. To generalize the existing recovery boiler and electricity generation operation for this model, steam requirements are simplified to only the energy flow without tracking steam pressures; electricity is produced at a fixed ratio $(6.7 \mathrm{GJ} / \mathrm{GJ}$ steam:electricity, is assumed in these results) by the recovery boiler system. Additional steam is then produced in the power boiler from the heating value of available residuals and added hog fuel feed when needed. Excess steam generation is converted to electricity in an auxiliary generator unit. Capital expenses are added for power boiler and auxiliary generator capacity, assumed to be covered by $70 \%$ existing capacity in the mill. Efficiency of the recovery boiler, power boiler, and auxiliary generator are 
assumed to be $65 \%, 80 \%$, and $40 \%$, respectively, with key heating value assumptions summarized in

Table 2.1

Table 2.1: Heating Value Assumptions

\begin{tabular}{|c|c|}
\hline Componenet/Stream & $\begin{array}{l}\text { Energy Value } \\
\text { (GJ/ton) }\end{array}$ \\
\hline \multicolumn{2}{|c|}{ Dissolved Liquor Components } \\
\hline Carbohydrates & 12.34 \\
\hline Lignin & 23.04 \\
\hline Extractives & 29.39 \\
\hline \multicolumn{2}{|l|}{ Process Streams } \\
\hline Fermentation Residuals & 10.08 \\
\hline Fuel Residuals & 39.46 \\
\hline Wood Residuals, dry basis & 18.99 \\
\hline
\end{tabular}

\subsubsection{Saccharification, Fermentation, and ATJ}

The conversion of pretreated pulp into liquid fuels for distribution involves several process areas: saccharification, enzyme production, fermentation, alcohol and residual solids separation, alcohol-to-jet, and production handling and storage. Saccharification, enzyme production, and fermentation units are based on the NREL Corn Stover to Ethanol Model[21]. Because of the levels of biomass recalcitrance present in woody biomass, particularly from softwoods, can vary and is highly dependent on the chemistry and severity of pretreatment operations, the yield of fermentable carbohydrates from saccharification is adjustable in the model and are presented across "Recalcitrance Levels" in the results. Higher recalcitrance indicates a more resilient cell structure and greater incidence of inhibitory components resulting in lower saccharification and fermentation yields, as is more typical for woody feedstocks. Recalcitrance level assumptions are described in Table 2.2, showing the percentage of the theoretical maximum yield chosen for saccharification and fermentation of both pentose and hexose sugars.

Table 2.2: Recalcitrance Level. Yields indicate \% of theoretical maximum

\begin{tabular}{|c|c|c|c|c|}
\hline $\begin{array}{c}\text { "Recalcitrance } \\
\text { Level" }\end{array}$ & $\begin{array}{c}\text { Saccharification Yield } \\
\text { hexose sugars }\end{array}$ & $\begin{array}{c}\text { Saccharification Yield } \\
\text { pentose sugars }\end{array}$ & $\begin{array}{c}\text { Fermentation Yield } \\
\text { hexose sugars }\end{array}$ & $\begin{array}{c}\text { Fermentation Yield } \\
\text { pentose sugars }\end{array}$ \\
\hline Low & $90 \%$ & $90 \%$ & $90 \%$ & $90 \%$ \\
\hline Medium & $85 \%$ & $85 \%$ & $85 \%$ & $85 \%$ \\
\hline High & $80 \%$ & $80 \%$ & $80 \%$ & $80 \%$ \\
\hline
\end{tabular}

An alcohol and residual solids separation unit is included to provide azeotropic (95.6\%) ethanol feed to ATJ. Further enrichment using molecular sieves is not necessary due to the requirements for the dehydration reactor system[6], and is not included. Additionally, this unit produces a lignin-rich filter cake from residual solids remaining after fermentation. These residuals are fed to the power boiler system for steam production. 
The alcohol-to-jet (ATJ) conversion unit converts an ethanol intermediate to a mixture of liquid fuels. Alternately, an isobutanol intermediate is capable of producing viable jet fuels, but is not evaluated in this model due to the greater availability of process data for ethanol production. This unit produces a mixture of hydrocarbon fuels, which are fractionated into gasoline/naphtha, jet, and diesel fuel portions assumed at a $10 \% / 70 \% / 20 \%$ ratio. Total yield of liquid fuels from this unit in the base case is $95 \%$ of the theoretical maximum ( $60.9 \%$ by mass) due to some requirement for purge streams and extra fractionation residuals; these residuals are all fed to the power boiler for steam generation. The selling price for gas/naphtha and diesel fuel are proportionately adjusted along with the jet fuel selling price based on historical price data[23].

\subsubsection{Extraction Unit Scenarios}

A wide number of technologies to produce fermentable sugars as a pulp mill co-product have been explored, including a number of strategies aiming to divert small portions of carbohydrate components with relatively little impact on fibers production. These chiefly target hemicellulose sugars because they are less critical than cellulose for fiber properties and provide less energy to the recovery boiler than lignin. Two strategies for hemicellulose extraction are explored in the integrated pulp biorefinery model as supplementary carbohydrate streams feeding fermentation: pre-extraction and black liquor fractionation.

Pre-extraction of hemicellulose prior to kraft pulping or prehydrolysis kraft process is a well established technology for dissolving pulp production [32]. Prehydrolysis kraft process utilizes existing pulping digesters, producing a dilute hydrolysate liquor containing carbohydrates mostly derived from hemicellulose. The prehydrolysis kraft process consists a few steps as illustrated in Figure 2.2. Details of hemicellulose pre-extraction process operations and conditions can be found in a number of previous works [8,10,24-26]. Mild acid or near-neutral processes are typical, which primarily target acetic groups and partially hydrolyze some carbohydrate components. In our models, a liquid:solid ratio of 4 and a 9:1 ratio of hemicellulose to cellulose components in the liquor are assumed. Particularly at lower yield conditions, additional evaporation is required to maintain a $20 \%$ solids loading to fermentation.

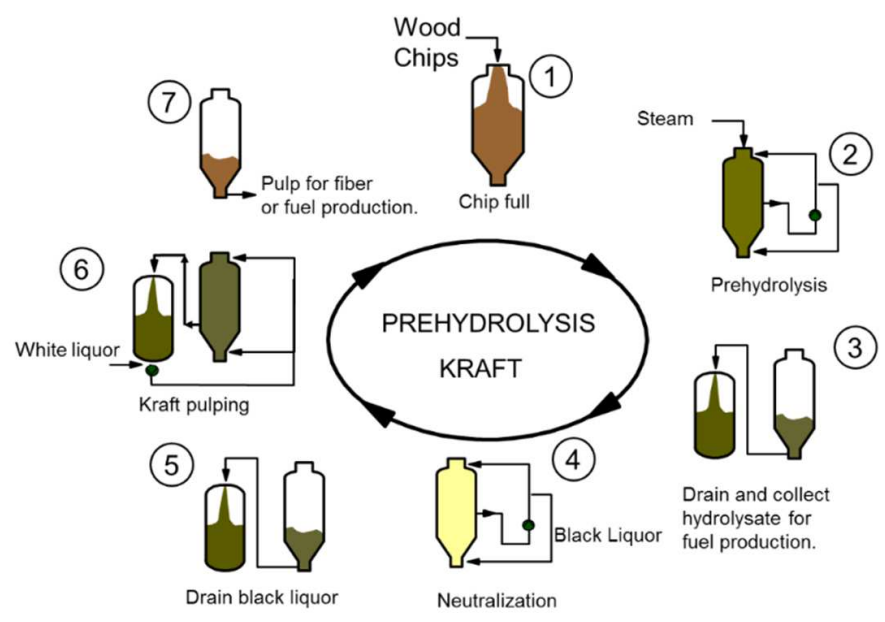

Figure 2.2 Hemicelluose pre-extraction (prehydrolysis) from wood chips prior to kraft pulping 
The black liquor fractionation model represents a unit designed to remove useful dissolved fragments from the black liquor before or after evaporation [27]. The process uses a variety of methods including extraction, precipitation, and membrane filtration aimed at selectively yielding biomass fragments or degradation compounds generated during pulping $[27,28]$. Although a substantial portion of carbohydrates solubilized during typical pulping operations are further degraded to sugar acids, this model is included in our analysis to represent potential scenarios in which pretreatment and extraction technology allows for fermentable carbohydrate recovery from black liquor. The scenarios shown describe a stream containing equal parts insoluble lignin and hemicellulose fragments.

\subsubsection{Economic Analysis}

The primary output of the model is the minimum selling price of jet fuel blendstock, with a net present value of zero after the plant's lifetime of 20 years. The model and financial assumptions are based on economic analyses by Bann, et. al., and Petter, et. al.[29,30]. This model assumes a 20 year plant lifetime with a 10 year $30 \%$ equity loan at $8 \%$ interest. $16.9 \%$ income taxes and $2 \%$ inflation are assumed along with $90 \%$ operational uptime. Base case assumptions for major materials and electricity credits are shown in Table 2.3.

Table 2.3: Major Price Assumptions

\begin{tabular}{|l|l|}
\cline { 2 - 2 } \multicolumn{1}{c|}{} & Price \\
\hline Electricity Price & $\$ 0.069 / \mathrm{kWh}$ \\
\hline Electricity Wholesale Credit & $\$ 0.037 / \mathrm{kWh}$ \\
\hline Feedstock (softwood) & $\$ 80 / \mathrm{ADT}$ \\
\hline Natural Gas & $\$ 4.24 / \mathrm{MMBTU}$ \\
\hline Hydrogen & $\$ 1.74 / \mathrm{kg}$ \\
\hline Hog Fuel & $\$ 45 /$ ton \\
\hline Cooling Water Generation & $\$ 0.354 / \mathrm{GJ}$ \\
\hline
\end{tabular}

Capital costs are estimated based on equipment costs for each unit and retrofitted unit used in the model, with installation and indirect costs applied using a factored approach to estimate additional direct and indirect costs from purchased equipment costs (PEC). The cost factors used are based on Peters and Timmerhaus [31] and amount to $302 \%$ of PEC for total direct costs and $126 \%$ of PEC for total indirect costs. These factors account for costs such as equipment installation and indirect costs for an add-on facility.

\section{Results and Discussion}

\subsection{Base Case Results}

In the base case scenario, a facility processing 1,000 ADT/day (air dry tons per day, with standard $10 \%$ moisture content) of softwood feedstock produces 29,500 thousand gallons of liquid fuel per day (10.2 million gallons per year, including 7.15 MMgal/yr jet fuel) alongside an equally fed bleached pulp production process. A summary of the operational and cashflow details for the base case is provided by Table 3.1 . 
In this data and in the following comparisons, "energy balance mode" refers to the consideration of energy consumption by brownstock production used in fiberline operations as well as energy generation due to black liquor produced by these processes. Because non-energy costs and revenue from fiber pulp production is not assumed in the whole mill scenarios, energy generation (fines and dissolved solids streams) and demands (steam and electricity) from these operations are projected onto the cost of production of fuels; these data offer a useful baseline to compare the scenarios shown in later sections in which the energy balance of fiber line operations are affected by fuels production. In the base case, fuels production alone provides a surplus of electricity partially offsetting a larger energy deficit from fiberline operations and resulting in a net purchase of electricity; steam and electricity balances are shown in Figure 3.1. 
Table 3.1: Operations and Cashflow Summary for base-case scenario (50\%/50\% fuels/fiber split)

\section{Operations Summary}

Fuels Production (gal/day)

Total Fuels Yield (gal/ton feed)

Steam Balance (GJ/day)*

Electricity Balance $(\mathrm{kW}) *$

Net Energy Yield (kWh/ton total feed)

\section{Cashflow Summary}

Total Capital Investment (MM\$)

Annual Operating Expenses

(MM\$)

Annual Revenue from Fuels

(MM\$)

Annual Revenue/Cost from

Electricity (MM\$)

Jet MSP \$/gal

*Electricity balance includes generation from excess steam (Steam Balance)

\begin{tabular}{|c|c|c|c|c|}
\hline \multirow[t]{3}{*}{$\begin{array}{c}\text { Fiberline } \\
\text { Pulping Energy }\end{array}$} & \multicolumn{2}{|c|}{$\begin{array}{l}\text { Low Recalcitrance Level } \\
\text { Fuels Conversion }\end{array}$} & \multicolumn{2}{|c|}{$\begin{array}{c}\text { High Recalcitrance Level } \\
\text { Fuels Conversion }\end{array}$} \\
\hline & \multicolumn{2}{|c|}{ Energy Balance Mode } & \multicolumn{2}{|c|}{ Energy Balance Mode } \\
\hline & Fuels Only & Whole Mill & Fuels Only & Whole Mill \\
\hline-- & 28770 & 28770 & 22784 & 22784 \\
\hline-- & 28.77 & 28.77 & 22.78 & 22.78 \\
\hline 249 & 1079 & 1328 & 1560 & 1808 \\
\hline-795 & 2056 & 1261 & 5762 & 4967 \\
\hline-19 & 49 & 15 & 138 & 60 \\
\hline & Fuels Only & Whole Mill & Fuels Only & Whole Mill \\
\hline-- & $\$ 152.2$ & $\$ 156.0$ & $\$ 147.5$ & $\$ 151.1$ \\
\hline & $\$ 48.6$ & $\$ 49.0$ & $\$ 47.6$ & $\$ 48.0$ \\
\hline & $\$ 66.7$ & $\$ 67.8$ & $\$ 64.2$ & $\$ 65.3$ \\
\hline-- & $\$ 0.6$ & $\$ 0.4$ & $\$ 1.7$ & $\$ 1.5$ \\
\hline-- & $\$ 7.10$ & $\$ 7.22$ & $\$ 8.63$ & $\$ 8.78$ \\
\hline
\end{tabular}

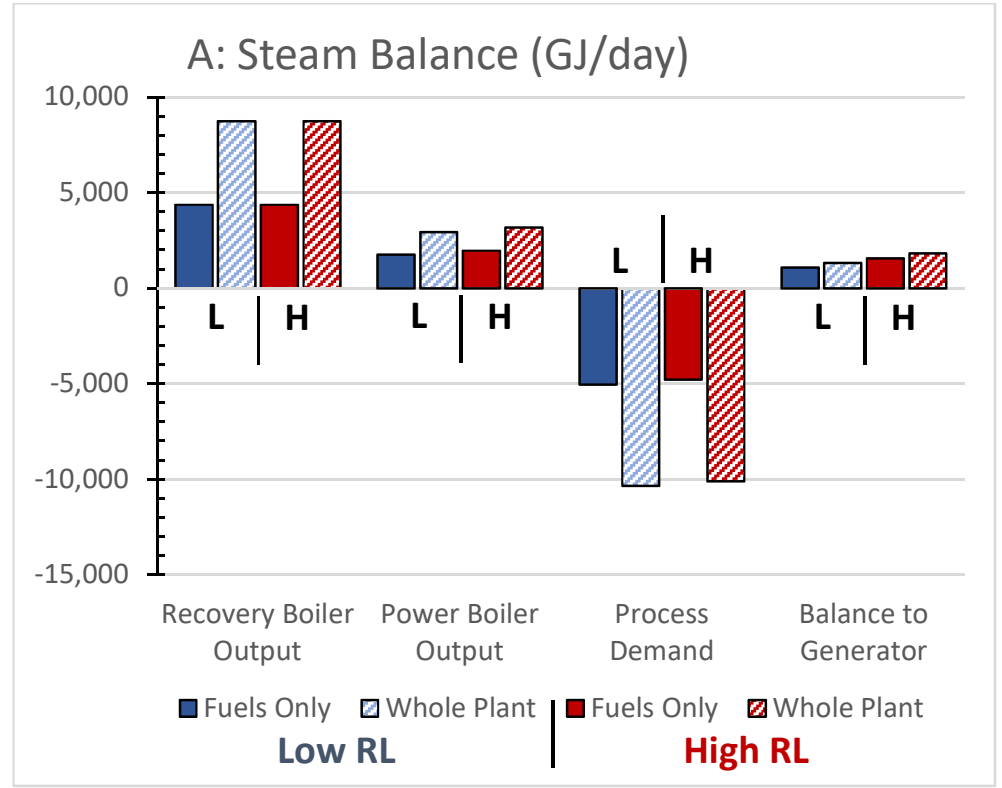




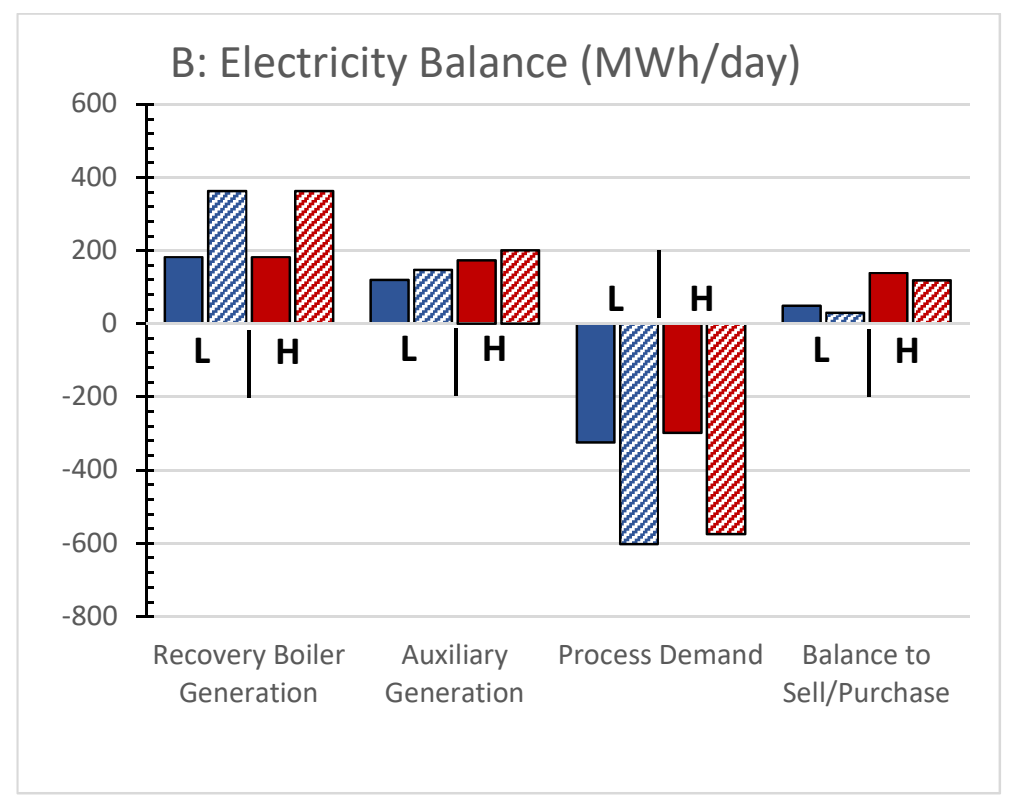

Figure 3.1: Energy Balances in Base Case Scenario (A) Steam Balance in GJ/day (B) Electricity Balance in $\mathrm{MWh}$ /day. Excess steam is converted to electricity under auxiliary generation. Higher brownstock recalcitrance levels $(H)$ offers marginally higher energy recovery than lower levels $(L)$

Figure 3.2 addresses the scale of the retrofit project, in terms of the portion of a complete 2,000 $A D T /$ day feed mill. Scenarios with higher percentage of feedstock directed toward fuels production in the mill achieve economic benefits in this model primarily due to improved economy of scale and reduced net mill-wide energy requirements.

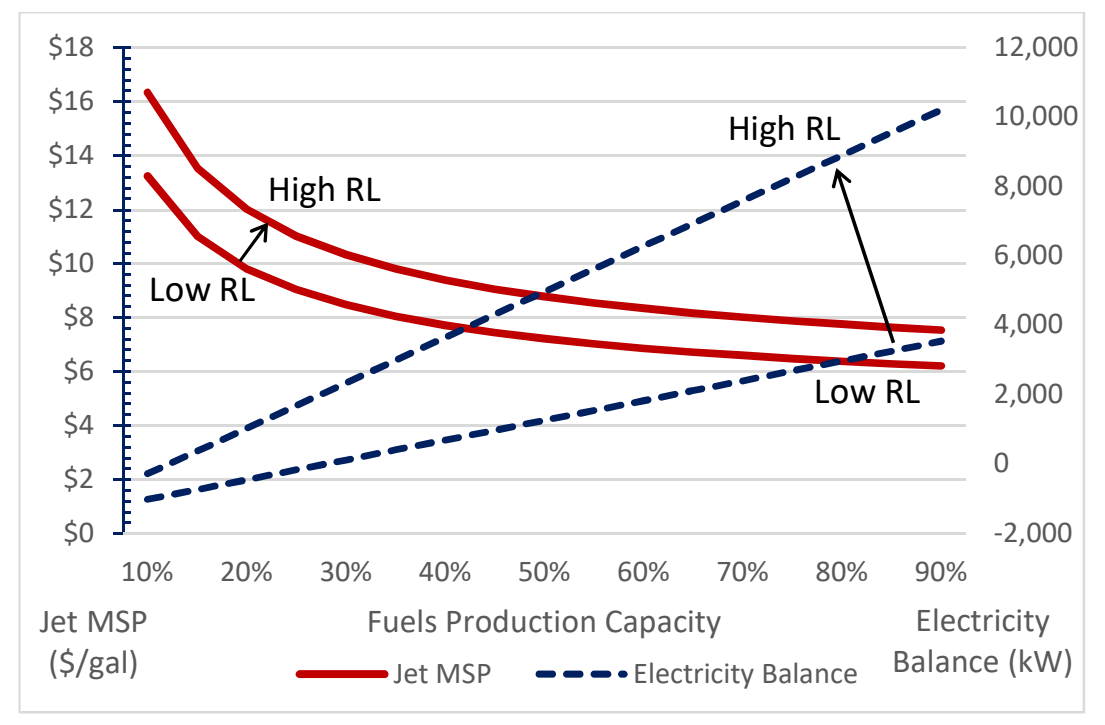




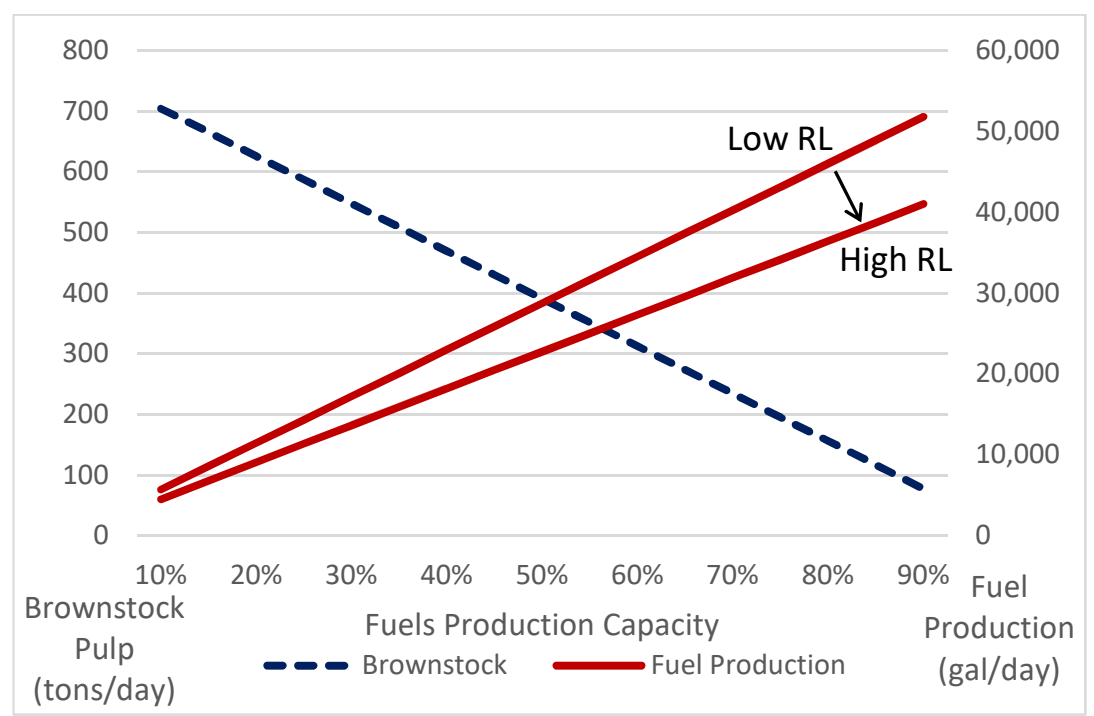

Figure 3.2: Effect of Production Split Towards Fuel in a 2,000 tons/day Feed Mill. A: Minimum Selling Price (MSP) Output and Electricity Balance, B: Production Trade-Off Between Fuels and Brownstock Pulp. RL: Brownstock Recalcitrance Level

While data in Figure 3.2 is presented as diversion of feedstock from a fixed total mill capacity, the modeled data can represent other scenarios than a mill diverting retired pulp capacity into fuels production. For example, a mill with excess chemical plant and recovery boiler capacity may utilize this capacity to support fuels conversion with increased total feedstock consumption for the mill. Part B of this figure demonstrates the direct trade-off between 30.4 gallons of liquid fuel or 0.437 tons of brownstock production per ton of feedstock in the modeled scenario.

\subsection{Extraction Unit Scenarios}

Scenarios testing the use of a hemicellulose pre-extraction for wood chips is shown in Table 3.2. These scenarios (in whole-plant energy balance mode) compare the addition of this unit to both the fuels and fiber production lines alone, both lines, and the base case scenario (no extraction). Direct capital and operating expenses incurred from operation of the pre-extraction unit itself is not included in this analysis, with the exception of steam required for evaporation of extraction liquor. The addition of the extraction unit provides more thorough utilization of carbohydrates to improve fuel output at a cost of the energy potentially recovered from these components. A high demand for steam is also incurred due to the need for evaporation of the extraction liquor; reduction in the liquid/solid ratio for pre-extraction ( 4 is assumed here) would improve steam economy.

The marginal benefit shown for adding pre-extraction to chips entering fuels production is smaller than for those for fiber processing. However, while the impact of pre-extraction is modeled downstream on pulp composition in the fuels line, its effect on fiber yield and properties is not considered in the model. A mild pre-extraction process with minimal impact on cellulose structure is important for fiberline feed in order to maintain pulp product production. Further assessment of preextraction with varying degrees of fiber degradation, and thus greater carbohydrate solubilization, is 
shown in Figure 3.3; as in previous cases, increases in fuel yield are accompanied by reduced steam and electricity generation.

Table 3.2: Pre-Extraction Scenarios: (5\% Extraction Rate, Low Recalcitrance Level)

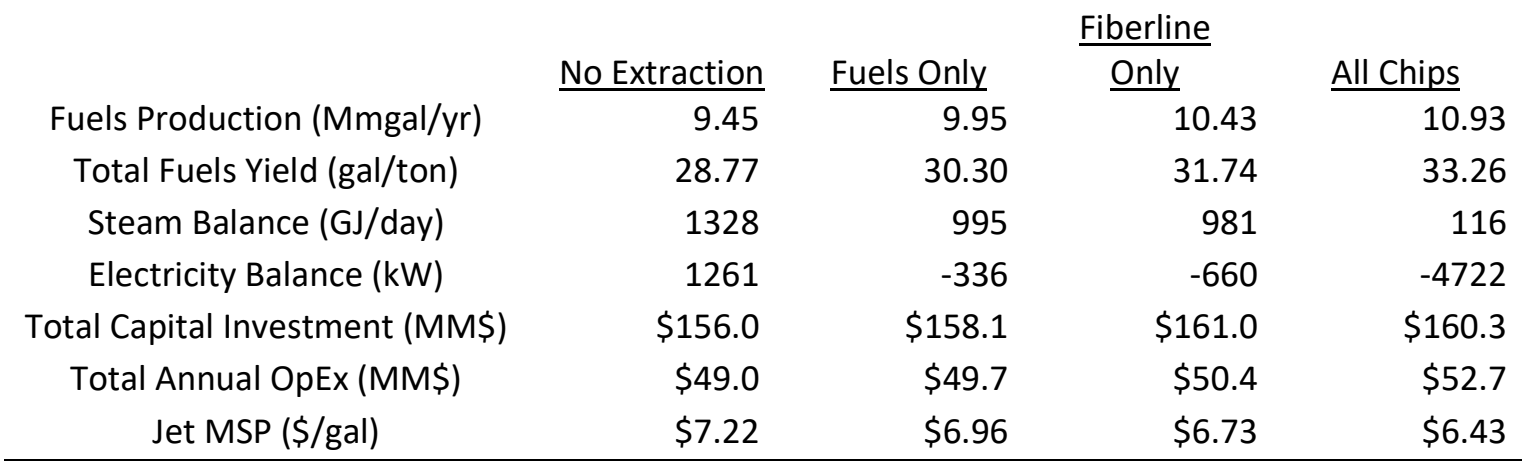
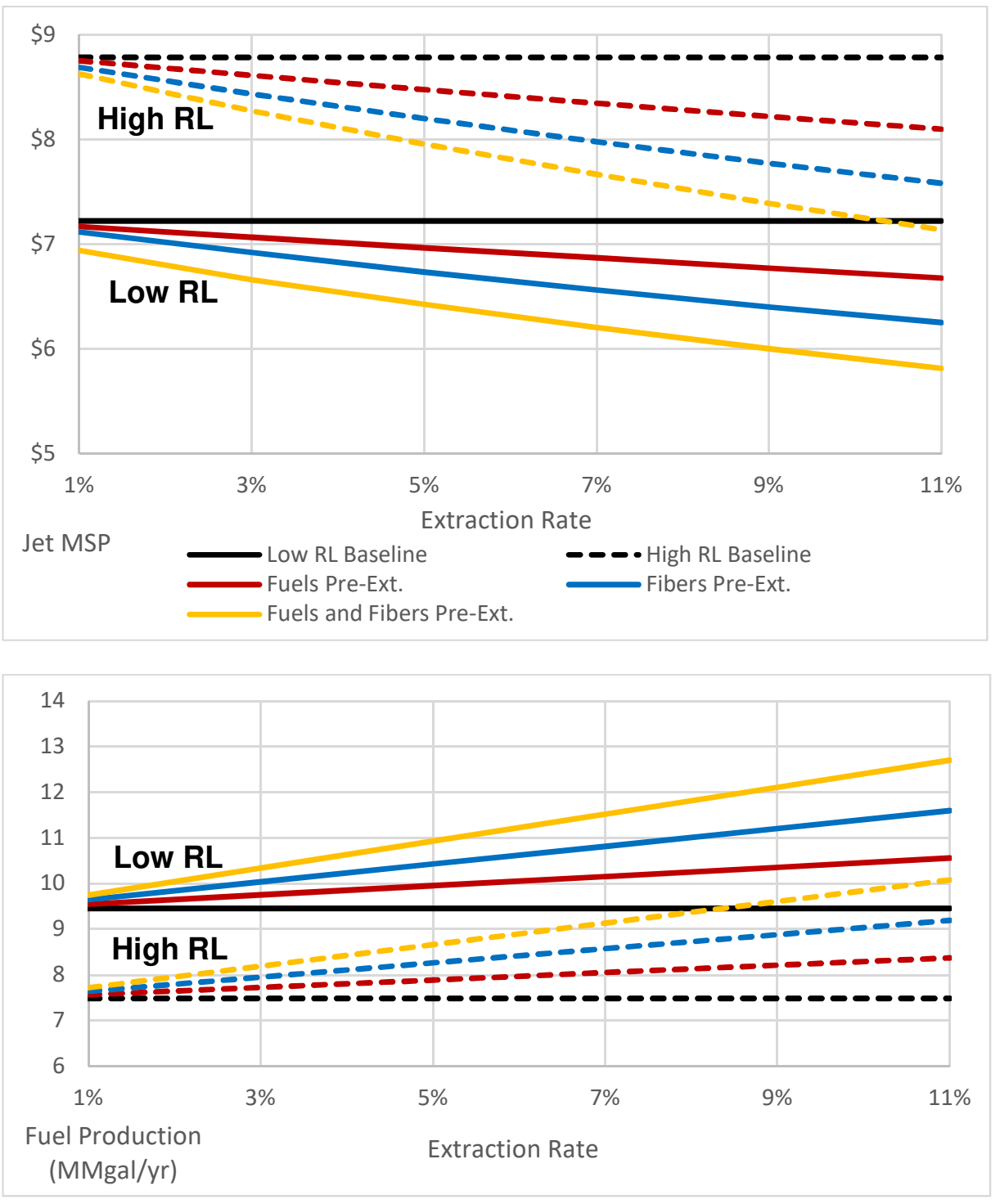
Figure 3.3: Effect of Pre-Extraction Rate on Jet MSP (top) and total liquid fuels production rate (bottom). MSP is given only for comparison between fuel yield and energy costs; it does not account for operation costs directly incurred by extraction.

Pre-extraction offers an attractive method to extract fermentable carbohydrates both from the fiber line and improve their utilization in chips entering the fuels line. Although direct costs for running a pre-extraction unit are not included in this analysis, a number of studies on this extraction method have demonstrated reasonable yield of carbohydrate oligomers with low impact on fiber properties and a relatively low degree of modification to digester operations (low capital and operating expenses)[24,32].

Similarly to pre-extraction, black liquor fractionation offers improvements in fuel production yield by diverting fermentable carbohydrates which would otherwise contribute to energy recovery. This addition, at a 5\% extraction/fractionation rate, alongside the base case scenarios is shown in Table 3.3; the whole mill model includes fractionation of liquor components from fiberline digesters not included in the fuel only analysis. Further examination of the yield of the fractionation process is provided by Table 3.4. As in the pre-extraction model, capital and operating costs incurred by the fractionation unit itself are not included in these results; MSP from the liquor fractionation model only predicts trade-offs between fuel and energy yield due to the fractionation unit.

Table 3.3: Black Liquor Fractionation Scenarios: (5\% Extraction Rate, Low Recalcitrance Level)

\begin{tabular}{lrrrrr} 
& \multicolumn{2}{c}{ Fuel Only } & \multicolumn{2}{c}{ Whole Mill } \\
& \multicolumn{1}{c}{ No } & & \multicolumn{1}{l}{ No } & \\
& \multicolumn{1}{l}{ Extraction } & & BL-Frac. & \multicolumn{1}{l}{ Extraction } & BL-Frac. \\
Fuels Production (MMgal/yr) & 9.45 & 9.95 & 9.45 & 10.45 \\
Total Fuels Yield (gal/ton) & 28.77 & 30.29 & 28.77 & 31.81 \\
Steam Balance (GJ/day) & 1079 & 752 & 1328 & 673 \\
Electricity Balance (kW) & 2056 & -261 & 1261 & -3372 \\
Total Capital Investment (MM\$) & $\$ 152.2$ & $\$ 156.0$ & $\$ 156.0$ & $\$ 163.8$ \\
Total Annual OpEx (MM\$) & $\$ 48.6$ & $\$ 49.5$ & $\$ 49.0$ & $\$ 52.5$ \\
Jet MSP (\$/gal) & $\$ 7.10$ & $\$ 6.93$ & $\$ 7.22$ & $\$ 6.81$
\end{tabular}

Table 3.4: Black Liquor Fractionation Scenarios by Fractionation Rate. Whole mill energy balance mode; low recalcitrance level. MSP is given only for comparison between fuel yield and energy costs; it does not account for operation costs directly incurred by the fractionation process.

\begin{tabular}{|c|c|c|c|c|c|c|}
\hline Fractionation Yield & $\underline{1 \%}$ & $\underline{3 \%}$ & $\underline{5 \%}$ & $\underline{7 \%}$ & $\underline{9 \%}$ & $\underline{11 \%}$ \\
\hline Jet MSP (\$/gal) & $\$ 7.15$ & $\$ 6.98$ & $\$ 6.81$ & $\$ 6.65$ & $\$ 6.48$ & $\$ 6.32$ \\
\hline Steam (GJ/day) & 1,197 & 935 & 673 & 411 & 149 & -113 \\
\hline Electricity Balance (kW) & 334 & -1519 & -3372 & -5225 & -7078 & -8407 \\
\hline Fuels Produced (MMgal/yr) & 9.65 & 10.05 & 10.45 & 10.85 & 11.25 & 11.65 \\
\hline
\end{tabular}




\subsection{Effect of Kappa Number}

The base case scenario is based on a softwood digestor producing kappa number 40 pulp at $48.3 \%$ yield. Some kraft mills, such as linerboard mills, utilize a milder digester process to produce higher kappa number pulps with greater lignin content and digester pulp yield, and reduced dissolved solids flow to recovery operations. Both saccharification and fermentation processes, however, are inhibited by the effects of higher lignin content and fiber structure integrity present in these less severely pretreated pulps.

To assess the impact of these effects on the integrated biorefinery model, process conditions were defined for digestor operations to produce high kappa pulp. A relationship between kappa and pulp yield of $0.23 \% / K$ was used for these data[33]. Inhibitory effects on saccharification due to additional lignin content were estimated at a reduction of up to $10 \%$ maximum yield from the base case at a kappa number of 100; a medium recalcitrance level was used for the base case (kappa \# 40). Results from this analysis are shown in Table 3.5. Table 3.6 presents combinations of high and low kappa number for both fuel and fiber production lines.

Table 3.5: Effect of Kappa Number changes on Fuels Only Base Case

$\begin{array}{lrrr}\text { Kappa Number } & \underline{40} & \underline{70} & \underline{100} \\ \text { Pulping/Pretreatment Yield } & 48.3 \% & 55.2 \% & 62.1 \% \\ \text { Fuels Production (MMgal/yr) } & 8.43 & 8.60 & 8.59 \\ \text { Total Fuels Yield (gal/ton) } & 25.66 & 26.19 & 26.15 \\ \text { Steam Balance (GJ/day) } & 1324 & 1093 & 902 \\ \text { Electricity Balance (kW) } & 3949 & 2330 & 1033 \\ \text { Total Capital Investment (MM\$) } & \$ 149.8 & \$ 154.4 & \$ 158.4 \\ \text { Total Annual OpEx (MM\$) } & \$ 48.1 & \$ 49.0 & \$ 49.8 \\ \text { Jet MSP (\$/gal) } & \$ 7.81 & \$ 7.88 & \$ 8.09\end{array}$

Table 3.6: High and Low Kappa Number variations for pretreatment and digester operations. 50\% production split base case

Kappa Number: Fuel;Fiber
Fuels Production (MMgal/yr)
Total Fuels Yield (gal/ton)
Steam Balance (GJ/day)
Electricity Balance (kW)
Total Capital Investment (MM\$)
Total Annual OpEx (MM\$)
Jet MSP (\$/gal)

Kappa Number: Fuel;Fiber

Fuels Production (MMgal/yr)

Steam Balance (GJ/day)

ce $(\mathrm{kW})$

Jet MSP (\$/gal) 
Under these assumptions, the model predicts a slight increase in fuels yield with increased kappa number operation through the fuels production line. Considering only this line, the associated reduction in energy recovery outweighs this benefit although they are approximately balanced throughout the whole facility. A detailed understanding of the effects of digester operations on downstream conversion processes is critical to accurately predicting these economics in a real facility.

\section{Conclusions and Recommendations}

The deeply integrated relationship between a pulp mill's chemical and energy recovery unit is critical to its sustainable and economic operation by minimizing the requirements of chemicals and energy to feed the mill. Although it remains an attractive strategy to improve the economics of an integrated biorefinery as well, it is still challenged by the generally high capital costs for the necessary equipment such as recovery boilers, turbogenerators, lime kilns, and recausticization plants.

This study showed for the first time that jet fuel with a MSP between $\$ 6$ to $\$ 8$ per gallon can be produced from an integrated process utilizing pulp mill assets. This jet MSP is much higher than current market jet fuel prices ( $\$ 2 /$ gal). The model presented in this study is intended primarily for evaluating the production capacity and energy balance of an ATJ-Pulp Mill Integrated Biorefinery at the facility level whereas the economic evaluation is provided based on a variety of predesign cost assumptions which offer a high margin of error. Although direct comparisons between the minimum selling prices calculated in these results and market prices are cautioned against, these results offer a useful basis to make assessments of technical opportunities from a business perspective.

Fuels are a low-price commodity historically produced alongside much higher value petrochemical products, so achieving strong economics in a biorefinery is challenging in any case. Especially when considering the opportunity cost of sacrificing potential pulp production (a relatively high value product), refits to mill infrastructure for fuels production is not guaranteed to be economically feasible particularly for large-volume changes to production. It should be noted that modern pulp mills already typically generate other co-products not accounted for in our comparisons, such as turpentine and tall oils extracted from wood; an integrated mill could preserve these product streams and continue to provide additional revenue.

Based on conclusions derived from the models described in this study, we offer the following recommendations for further investigation into forest biorefineries for liquid fuel production:

- Although achieving a selling price competitive with conventional jet fuel will remain a barrier, pulp mill integration is an attractive solution to reduce integrated biorefinery processing costs when "drop-in" fuel upgrading processes are included

- The application of Kraft pulp digester equipment for biomass pretreatment and ethanol fermentation should be further explored to refine the understanding of their performance, capital costs, and operating requirements in these scenarios

- Integrated forest biorefineries will benefit by the use of multiple cost and energy efficient technologies to fractionate fermentable carbohydrates from residual combustibles, maximizing both product and energy yield 
As markets shift away from the use of fossil fuels and petrochemical products due to rising oil prices or a desire for renewable and domestic feedstocks, industries relying on high energy density fuels such as aviation are finding the need to out alternative sources to sustain them. Alongside shifts in modern demand for pulp and paper products, there is an opportunity to bridge the gap between these two industries and forge a new supply chain, providing access for the pulp industry to enter alternative markets.

\section{Acknowledgements}

The authors gratefully acknowledge funding from the Northwest Advanced Renewables Alliance (NARA), supported by the Agriculture and Food Research Initiative Competitive Grant no. 2011-6800530416 from the USDA National Institute of Food and Agriculture, as well as the U.S. Federal Aviation Administration Office of Environment and Energy under 13-C-AJFE-WaSU ASCENT project COE-2014-01. The project was managed by James Hileman and Nathan Brown.

\section{References}

[1] FAA, U.S. Aviation Greenhouse Gas Emissions Reduction Plan, 2012.

[2] U.S. Department of Energy - DOE -, Alternative Aviation Fuels: Overview of Challenges, Opportunities, and Next Steps, 2017. https://www.energy.gov/sites/prod/files/2017/03/f34/alternative_aviation_fuels_report.pdf.

[3] M.D. Staples, R. Malina, P. Suresh, J.I. Hileman, S.R.H. Barrett, Aviation $\mathrm{CO} 2$ emissions reductions from the use of alternative jet fuels, Energy Policy. 114 (2018) 342-354. doi:10.1016/J.ENPOL.2017.12.007.

[4] T. Radich, The Flight Paths for Biojet Fuel, 2015. http://www.eia.gov/workingpapers/pdf/flightpaths_biojetffuel.pdf (accessed October 20, 2016).

[5] ASTM, Standard Specification for Aviation Turbine Fuel Containing Synthesized Hydrocarbons, 2017. doi:10.1520/D1655-10.2.

[6] S. Geleynse, K. Brandt, M. Garcia-Perez, M. Wolcott, X. Zhang, The Alcohol-to-Jet Conversion Pathway for Drop-In Biofuels: Techno-Economic Evaluation, ChemSusChem. 11 (2018) 37283741. doi:10.1002/cssc.201801690.

[7] A.J. Ragauskas, M. Nagy, D.H. Kim, C.A. Eckert, J.P. Hallett, C.L. Liotta, From wood to fuels: Integrating biofuels and pulp production, Ind. Biotechnol. 2 (2006) 55-65. doi:10.1089/ind.2006.2.55.

[8] M. Marinova, E. Mateos-Espejel, N. Jemaa, J. Paris, Addressing the increased energy demand of a Kraft mill biorefinery: The hemicellulose extraction case, Chem. Eng. Res. Des. 87 (2009) 12691275. doi:10.1016/J.CHERD.2009.04.017.

[9] M. Johnson, P. Hart, Integrating a biorefinery into an operating kraft mill, Bioresources. 11 (2016).

[10] H.J. Huang, S. Ramaswamy, W.W. Al-Dajani, U. Tschirner, Process modeling and analysis of pulp 
mill-based integrated biorefinery with hemicellulose pre-extraction for ethanol production: A comparative study, Bioresour. Technol. 101 (2010) 624-631. doi:10.1016/j.biortech.2009.07.092.

[11] V. Lundberg, E. Axelsson, M. Mahmoudkhani, T. Berntsson, Process integration of near-neutral hemicellulose extraction in a Scandinavian kraft pulp mill - Consequences for the steam and $\mathrm{Na} / \mathrm{S}$ balances, Appl. Therm. Eng. 43 (2012) 42-50. doi:10.1016/J.APPLTHERMALENG.2012.03.037.

[12] R. Fornell, T. Berntsson, Process integration study of a kraft pulp mill converted to an ethanol production plant - Part A: Potential for heat integration of thermal separation units, Appl. Therm. Eng. 35 (2012) 81-90. doi:10.1016/J.APPLTHERMALENG.2011.10.010.

[13] R. Fornell, T. Berntsson, A. Åsblad, Process integration study of a kraft pulp mill converted to an ethanol production plant - part B: Techno-economic analysis, Appl. Therm. Eng. 42 (2012) 179190. doi:10.1016/J.APPLTHERMALENG.2012.02.043.

[14] A. Van Heiningen, Converting a kraft pulp mill into an Integrated Forest BioRefinery ( IFBR ), Pulp Pap. Canada. 107 (2000) 1-6.

[15] X. Zhang, M.G. Paice, J. Deng, Modify Existing Pulp and Paper Mills for Biorefinery Operations, in: 2011: pp. 395-408. doi:10.1021/bk-2011-1067.ch015.

[16] R.B. Phillips, H. Jameel, H.M. Chang, Integration of pulp and paper technology with bioethanol production, Biotechnol. Biofuels. 6 (2013) 13. doi:10.1186/1754-6834-6-13.

[17] B. Ben Daya, M. Nourelfath, Sustainability assessment of integrated forest biorefinery implemented in Canadian pulp and paper mills, Int. J. Prod. Econ. (2018). doi:10.1016/J.IJPE.2018.06.014.

[18] D. Silva Braz, A. Pinto Mariano, Jet fuel production in eucalyptus pulp mills: Economics and carbon footprint of ethanol vs. butanol pathway, Bioresour. Technol. 268 (2018) 9-19. doi:10.1016/J.BIORTECH.2018.07.102.

[19] Z. Wang, S. Winestrand, T. Gillgren, L.J. Jönsson, Chemical and structural factors influencing enzymatic saccharification of wood from aspen, birch and spruce, Biomass and Bioenergy. 109 (2018) 125-134. doi:10.1016/J.BIOMBIOE.2017.12.020.

[20] P.J. Ince, Computer Model for Economic Study of Unbleached Kraft Paperboard Production, 1984.

[21] D. Humbird, R. Davis, L. Tao, C. Kinchin, D. Hsu, A. Aden, P. Schoen, J. Lukas, B. Olthof, M. Worley, D. Sexton, D. Dudgeon, Process Design and Economics for Biochemical Conversion of Lignocellulosic Biomass to Ethanol, Renew. Energy. 303 (2011) 147. doi:10.2172/1013269.

[22] AGRA Simons, Duncan Industrial, Ecole Polytechnique, NLK Consultants, Sandwell Inc., SodeXpro, W. Automation, Energy Cost Reduction in the Pulp and Paper Industry, Pulp and Paper Research Institute of Canada, Montreal, 1999.

[23] EIA, U.S. Refinery Petroleum Product Prices, EIA. (2013).

https://www.eia.gov/dnav/pet/pet_pri_refoth_dcu_nus_m.htm (accessed May 1, 2018).

[24] S.L. Walton, D. Hutto, J.M. Genco, G.P. Van Walsum, A.R.P. Van Heiningen, Pre-extraction of hemicelluloses from hardwood chips using an alkaline wood pulping solution followed by kraft 
pulping of the extracted wood chips, Ind. Eng. Chem. Res. 49 (2010) 12638-12645.

doi:10.1021/ie100848p.

[25] H. Mao, J.M. Genco, S.-H. Yoon, A. van Heiningen, H. Pendse, Technical Economic Evaluation of a Hardwood Biorefinery Using the \&quot;Near-Neutral\&quot; Hemicellulose Pre-Extraction Process, J. Biobased Mater. Bioenergy. 2 (2008) 177-185. doi:10.1166/jbmb.2008.309.

[26] B. Yang, B. Wang, G. Wang, Z. He, Y. Ni, Integrated Forest Biorefinery: Value-added Utilization of Dissolved Organics in the Prehydrolysis Liquor of Prehydrolysis Kraft (PHK) Dissolving Pulp Production, Pap. Biomater. 3 (2018) 47-58.

[27] S. Mesfun, J. Lundgren, C.E. Grip, A. Toffolo, R.L.K. Nilsson, U. Rova, Black liquor fractionation for biofuels production - A techno-economic assessment, Bioresour. Technol. 166 (2014) 508-517. doi:10.1016/j.biortech.2014.05.062.

[28] A. Toledano, A. García, I. Mondragon, J. Labidi, Lignin separation and fractionation by ultrafiltration, Sep. Purif. Technol. 71 (2010) 38-43. doi:10.1016/J.SEPPUR.2009.10.024.

[29] S.J. Bann, R. Malina, M.D. Staples, P. Suresh, M. Pearlson, W.E. Tyner, J.I. Hileman, S. Barrett, The costs of production of alternative jet fuel: A harmonized stochastic assessment, Bioresour. Technol. 227 (2017) 179-187. doi:10.1016/j.biortech.2016.12.032.

[30] R. Petter, W.E. Tyner, Technoeconomic and Policy Analysis for Corn Stover Biofuels, ISRN Econ. 2014 (2014) 1-13. doi:10.1155/2020.

[31] Peters, Timmerhaus, Plant Design and Economics for Chemical Engineers, 2004.

[32] T. Radiotis, X. Zhang, M. Paice, V. Byrne, Optimizing Hardwood Prehydrolysis for Simultaneous Production of Bioproducts and Biomaterials, J. Bioprocess Eng. Biorefinery. 1 (2012) 69-76. doi:10.1166/jbeb.2012.1006.

[33] M. MacLeod, The top ten factors in kraft pulp yield, Pap. Timber. 89 (2007). 
Integrated Pulping and Recovery Operations

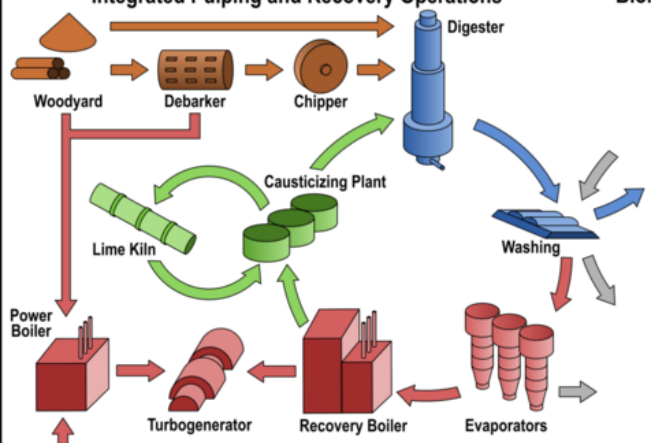

\section{Alcohol-to-Jet (ATJ) Process}

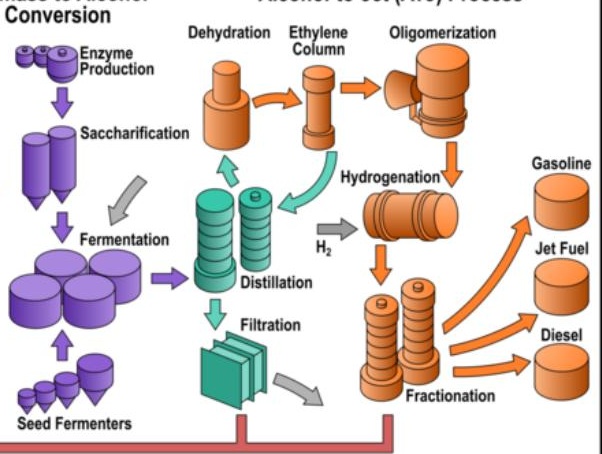

